\title{
Epidemiologic Study of Dental Caries Experience and Between-Meal Eating Patterns
}

\author{
R. A. BAGRAMIAN and A. L. RUSSELL \\ School of Dentistry, University of Michigan, Ann Arbor, Michigan 48104, USA
}

The relationship between dental caries and between-meal snacks was investigated in a study of 1,486 high school students. The participants completed a questionnaire on between-meal habits and then were given dental examinations. The lack of differences in dental caries between racial and geographic groups was not related to the frequency of sucrose-containing, between-meal snacks.

Dental caries has been designated as a bacterial disease, although there is no agreement as to the specific etiologic organisms involved. ${ }^{1}$ As a result of recent research, information on the mechanism of the activity of caries and the organisms concerned has been obtained. Bacteria, such as streptococcus strains, have been found to cause lesions on the smooth surfaces of animals' teeth; bacteria are dependent only on sucrose for the production of dextrans. ${ }^{2,3}$ Dextran binds bacteria together and causes them to stick to the teeth; sucrose is the principal substrate for the production of acids that attack and destroy the substance of the teeth. ${ }^{4}$ Consistent with these findings is the fact that the progress of lesions in populations is related directly to the presence and frequent use of sticky sugars in the diet. ${ }^{5}$ Prevalence of caries has been associated with the amount and frequency of high sucrose-containing, between-meal snacks. ${ }^{6}$ Caries experience is associated with betweenmeal eating so that differences or lack of differences between racial and geographic groups might be related to the amount and

Based on a thesis submitted to the School of Public Health, University of Michigan, in partial fulfillment of the requirements for the $\mathrm{PhD}$ degree.

This investigation was supported in part by USPHS

Research Training Grant 5 T01 DH 02005 from the

National Institutes of Health, Bethesda, Md.

Received for publication February 16, 1972. frequency of sucrose-containing betweenmeal snacks. The purpose of this study was to test the hypothesis that dental caries is related to the consumption of sucrosecontaining between-meal snacks.

\section{Materials and Methods}

A total of 1,486 white and black high school students in Detroit, Michigan and Columbia, South Carolina who were 14 to 17 years of age completed a questionnaire on between-meal eating habits. They then were examined for dental caries.

Dental examinations were conducted with the aid of a portable chair and a dental spotlight; radiographs were not used. Caries experience was recorded by use of the Klein and Palmer code. ${ }^{7}$ Only obvious lesions in which soft dentin could be detected were recorded as carious. An assistant recorded the dental findings.

The drinking waters of both cities contained no fluoride until about one year before the survey. To obviate the effect of ingestion of fluoride on the prevalence of caries, only residents who had consistently used the city's water since birth were included in the sample. The effect of outside sources of fluoride was controlled by the information on residency and permission slips and by questioning the participants. Some participants were excluded as a result of incomplete histories or because they had used water other than the city's.

Total caries experience, as indicated by DMF teeth, may not be related closely to the consumption of sucrose, because all lesions that are found in the mouth are included. This problem was anticipated in the early stages of the study, and therefore, dental data also were recorded and coded according to smooth surface and proximal lesions. The DMF teeth of each person and 
the mean DMF teeth of each group were calculated according to age, sex, race, and geographic location.

Information about the amount and frequency of consumed sucrose-containing between-meal snacks and cariogenic foodstuffs was gathered by use of a self-administered questionnaire. The questionnaire was easily understood and it was filled out as indicated during previous pretests. Standardized conditions were used to ensure uniformity before a dental examination was given.

The main purpose of the questionnaire was to determine snacking patterns in the form of between-meal eating habits. The students were asked to indicate if food items, such as candy, cake, ice cream, bread, crackers, and so forth were never eaten, sometimes eaten, or usually eaten between meals. The study design was intended to determine a general pattern, rather than attempt to acquire information that concerned specific amounts of consumed food. The prevalence of caries experience was compared with differences in between-meal patterns of eating, particularly the frequency and types of sucrose-containing foods.

\section{Results}

Findings for the analysis of DMF teeth are indicated in Table 1 and have been discussed in a previous report. 8 In Detroit, significant differences were found for race and age, but there was no significant difference between the sexes. No significant differences were found in data from Columbia. When taken as a whole, the mean DMF teeth for Columbia was slightly higher than the mean value for Detroit.

The results from the questionnaire about between-meal eating were examined to determine if a difference or a lack of difference found in caries experience could be associated with the frequency and amount of high sucrose snacks.

Several preliminary analyses were conducted to determine if patterns of response followed specific trends. A review of several hundred questionnaires resulted in a decision to classify responses according to the presence or absence of sucrose. Specific items were categorized as sticky sugar, sugar, and low sugar. The results of a preliminary analysis are shown in Table 2 . This classif-

TABLE 1

MEAN Numbers of DMF TEETH

\begin{tabular}{|c|c|c|c|c|c|c|}
\hline \multirow{2}{*}{$\begin{array}{c}\text { Age } \\
\text { Groups }\end{array}$} & \multicolumn{3}{|c|}{ White } & \multicolumn{3}{|c|}{ Black } \\
\hline & No. & Mean & $\mathrm{SD}^{*}$ & No. & Mean & $\mathrm{SD}$ \\
\hline \multicolumn{7}{|c|}{ Males in Detroit } \\
\hline $\begin{array}{l}14 \\
15 \\
16 \\
17\end{array}$ & $\begin{array}{l}30 \\
39 \\
18 \\
21\end{array}$ & $\begin{array}{l}11.13 \\
10.56 \\
10.39 \\
11.33\end{array}$ & $\begin{array}{l}5.19 \\
5.10 \\
4.37 \\
2.82\end{array}$ & $\begin{array}{l}55 \\
47 \\
32 \\
16\end{array}$ & $\begin{array}{r}8.56 \\
8.85 \\
10.22 \\
10.19\end{array}$ & $\begin{array}{l}4.00 \\
3.71 \\
4.69 \\
3.76\end{array}$ \\
\hline All ages & 108 & 10.85 & $\cdots$ & 150 & 9.45 & $\cdots$ \\
\hline \multicolumn{7}{|c|}{ Males in Columbia } \\
\hline $\begin{array}{l}14 \\
15 \\
16 \\
17\end{array}$ & $\begin{array}{l}32 \\
61 \\
36 \\
29\end{array}$ & $\begin{array}{r}10.81 \\
9.23 \\
12.28 \\
10.79\end{array}$ & $\begin{array}{l}4.31 \\
3.76 \\
4.27 \\
4.25\end{array}$ & $\begin{array}{l}61 \\
64 \\
42 \\
30\end{array}$ & $\begin{array}{l}10.34 \\
11.37 \\
11.10 \\
11.47\end{array}$ & $\begin{array}{l}4.20 \\
3.90 \\
3.61 \\
5.35\end{array}$ \\
\hline All ages & 158 & 10.78 & $\cdots$ & 197 & 11.07 & $\ldots$ \\
\hline \multicolumn{7}{|c|}{ Females in Detroit } \\
\hline $\begin{array}{l}14 \\
15 \\
16 \\
17\end{array}$ & $\begin{array}{l}27 \\
38 \\
25 \\
18\end{array}$ & $\begin{array}{l}10.15 \\
11.39 \\
12.00 \\
12.83\end{array}$ & $\begin{array}{l}3.33 \\
3.75 \\
3.91 \\
4.62\end{array}$ & $\begin{array}{r}92 \\
105 \\
57 \\
24\end{array}$ & $\begin{array}{r}8.61 \\
8.74 \\
11.11 \\
10.67\end{array}$ & $\begin{array}{l}4.10 \\
3.97 \\
5.40 \\
4.85\end{array}$ \\
\hline All ages & 108 & 11.59 & $\cdots$ & 278 & 9.78 & $\cdots$ \\
\hline \multicolumn{7}{|c|}{ Females in Columbia } \\
\hline $\begin{array}{l}14 \\
15 \\
16 \\
17\end{array}$ & $\begin{array}{l}32 \\
55 \\
73 \\
31\end{array}$ & $\begin{array}{l}11.16 \\
11.13 \\
11.08 \\
10.23\end{array}$ & $\begin{array}{l}3.59 \\
5.43 \\
3.98 \\
4.36\end{array}$ & $\begin{array}{r}74 \\
103 \\
76 \\
43\end{array}$ & $\begin{array}{l}11.07 \\
10.71 \\
11.61 \\
11.84\end{array}$ & $\begin{array}{l}3.98 \\
4.28 \\
4.67 \\
4.39\end{array}$ \\
\hline All ages & 191 & 10.89 & $\ldots$ & 296 & 11.20 & $\ldots$ \\
\hline
\end{tabular}

* SD, standard deviation. 
TABLE 2

SNacks Consumed by 15-Year-Old Black Females From Columbia

\begin{tabular}{ll}
\hline \hline Favorite Snack & Classification \\
\hline Candy & Sticky sugar \\
Cookies & Sticky sugar \\
Cake & Sticky sugar \\
Soda pop & Sugar \\
Ice cream & Sugar \\
Gum & Sugar \\
Chocolate milk & Sugar \\
Potato chips & Low sugar \\
Apples & Low sugar \\
Hot dogs & Low sugar \\
Hamburgers & Low sugar \\
Milk & Low sugar \\
Cheeseburgers & Low sugar \\
Sandwiches & Low sugar \\
Fish sandwich & Low sugar \\
Orange juice & Low sugar \\
Grapes & Low sugar \\
Crackers & Low sugar \\
\hline
\end{tabular}

Note: Total number of individuals who responded was 100.

cation corresponded to the hypothesis that persons with a high caries experience would have consumed more sugars and sticky sugars than persons with a low caries experience.

Because the plotted frequencies of DMF teeth showed approximately normal distributions, data could be separated into low, medium, and high caries experience according to the mean and a half standard deviation above and below the mean. Those scores that were greater than a half standard deviation were designated as high caries experience, those a half less were designated as low, and those within a half standard deviation were designated as medium. The dental data were separated initially by age, sex, race, and location. Because the data were separated, ages, sexes, races, and locations could be combined for further analysis based on low, medium, and high caries experience; data separation also minimized the effect of longer exposure of the teeth of older age groups to carious attack.

Chi-squares were calculated to determine if the differences in total caries experience (DMF teeth) were associated with snacking habits, as elicited by 25 items on the questionnaire for white and black males and females in Detroit and Columbia. Two hundred chi-squares were calculated. Although 14 of the chi-squares indicated significant differences, only 6 of these were significant with regard to the pattern of the hypothesis, ie, that caries experience would be higher for groups that reported more frequent use of sucrose-containing snack items.

The next step in the analysis was to examine the relationship between the responses from the questionnaire and the number of low, medium, and high proximal lesions.

Because of this non-normal data, the usual statistical calculation of the mean and standard deviations could not be used. The group with no lesions was designated as low caries activity. The remainder of the individuals were combined, a mean was calculated, and then the group was separated into medium and high caries activity according to this mean. On this basis, the computer was programmed to indicate the relationship of the responses from the questionnaire to low, medium, and high caries activity by age, sex, race, and location. These individual groupings then were combined by age, then by sex, then by race, and finally by location.

Chi-squares were calculated to test for significant relationships of responses on between-meal eating patterns that were indicated in the questionnaire to low, medium, and high proximal caries experience. These calculations were done for anterior proximal, posterior proximal, and anterior and posterior proximal caries experience. Tests were done according to sex and race for both Detroit and Columbia.

Chi-squares were calculated to determine if differences in proximal caries experience were associated with snacking habits, as elicited by 25 items on the questionnaire for white and black, males and females in Detroit and Columbia. Six hundred chisquares were calculated. Although 61 of the chi-squares indicated significant differences, only 36 of these were significant with a regard to the hypothesis, ie, that caries experience would be higher for groups that reported more frequent use of sucrosecontaining snack items.

Chi-squares then were calculated to determine if differences or lack of differences in caries experience between whites and blacks were related to snacking habits, as elicited by 25 items on the questionnaire. Entire groups of whites were compared with entire groups of blacks in Detroit and Columbia. Fifty chi-squares were calculated. Most of these analyses indicated that there were 
significant differences between whites and blacks in snacking patterns as reported in the questionnaire. Caries experience in Detroit was somewhat higher for whites than blacks (11.22 DMF teeth vs 9.31 DMF teeth). Therefore, it would be expected that more white than black children consumed sucrose items. Among the 25 chi-squares calculated for Detroit, 16 were statistically significant. Only six of these significant chisquares, however, indicated that the pattern of response was consistent with the hypothesis that blacks would consume less sugar-containing and more nonsugar-containing items (Table 3 ).

Unlike Detroit, caries experience in Columbia was similar for whites and blacks (10.74 DMF teeth vs 11.14 DMF teeth).
Chi-squares would be expected to show little difference in snacking patterns between whites and blacks.

But, 24 of the 25 chi-squares that were calculated for Columbia indicated considerable differences in snacking habits between white and black children. In 14 of the significant chi-squares, black children reported that they consumed more sucrose items and less nonsucrose items than white children (Table 4).

\section{Discussion}

Studies with isolated populations, such as Fisher's report ${ }^{9}$ on Tristan da Cunha, have demonstrated that as a population changes its way of life, which includes dietary habits and sharp increases in the consumption of

TABLE 3

Significant Differences Favoring or Opposing Hypothesis That Consumption of Sucrose Between Meals Is Associated With a Higher Caries Experience In White Children (Detroit)

\begin{tabular}{|c|c|c|c|c|}
\hline \multicolumn{4}{|c|}{ Significant Chi-square Values } & \multirow[b]{3}{*}{ Nonsignificant Chi-square } \\
\hline \multicolumn{2}{|c|}{ Favor Hypothesis } & \multicolumn{2}{|c|}{ Do Not Favor Hypothesis } & \\
\hline Item & P Value & Item & $P$ Value & \\
\hline $\begin{array}{l}\text { Usual snack } \\
\text { Breakfast cereal } \\
\text { Sweet potatoes } \\
\text { Potato chips } \\
\text { Crackers } \\
\text { Bread }\end{array}$ & $\begin{array}{l}<0.001 \\
<0.001 \\
<0.001 \\
<0.001 \\
<0.05 \\
<0.05\end{array}$ & $\begin{array}{l}\text { Spending money } \\
\text { Between-meal } \\
\quad \text { frequency } \\
\text { Favorite snack } \\
\text { Candy } \\
\text { Cake } \\
\text { Gum } \\
\text { Jelly } \\
\text { Cookies } \\
\text { Pie } \\
\text { Ice cream }\end{array}$ & $\begin{array}{l}<0.001 \\
<0.01 \\
<0.10 \\
<0.001 \\
<0.001 \\
<0.001 \\
<0.001 \\
<0.001 \\
<0.001 \\
<0.001\end{array}$ & $\begin{array}{l}\text { No. of meals eaten } \\
\text { Snack like to eat } \\
\text { Pop } \\
\text { Peanut butter } \\
\quad \text { sandwich } \\
\text { Fresh fruit } \\
\text { Milk } \\
\text { Tea } \\
\text { Other snacks } \\
\text { Food eaten every } \\
\quad \text { day }\end{array}$ \\
\hline
\end{tabular}

TABLE 4

Significant Differences in Reported Between-Meal SNacking of White and Black Children in Columbia

\begin{tabular}{|c|c|c|c|c|}
\hline \multicolumn{4}{|c|}{ Significant Chi-Square Values } & \multirow{3}{*}{$\begin{array}{l}\text { Nonsignificant Chi-Square, } \\
\text { Neither Group Favoring Sucrose }\end{array}$} \\
\hline \multicolumn{2}{|c|}{ Whites Favoring More Sucrose } & \multicolumn{2}{|c|}{ Blacks Favoring More Sucrose } & \\
\hline Item & $\mathrm{P}$ Value & Item & P Value & \\
\hline $\begin{array}{l}\text { Usual snack } \\
\text { Pop } \\
\text { Peanut butter } \\
\quad \text { sandwich } \\
\text { Breakfast cereal } \\
\text { Sweet potatoes } \\
\text { Potato chips } \\
\text { Bread } \\
\text { Fresh fruit } \\
\text { Milk } \\
\text { Tea }\end{array}$ & $\begin{array}{l}<0.001 \\
<0.02 \\
<0.05 \\
<0.001 \\
<0.001 \\
<0.001 \\
<0.001 \\
<0.001 \\
<0.01 \\
<0.001\end{array}$ & $\begin{array}{l}\text { Spending money } \\
\text { Number of meals } \\
\quad \text { eaten } \\
\text { Snack like to eat } \\
\text { Between-meal } \\
\quad \text { frequency } \\
\text { Favorite snack } \\
\text { Candy } \\
\text { Cake } \\
\text { Gum } \\
\text { Jelly } \\
\text { Cookies } \\
\text { Crackers } \\
\text { Pie } \\
\text { Ice cream } \\
\text { Other snacks }\end{array}$ & $\begin{array}{l}<0.001 \\
<0.001 \\
<0.001 \\
<0.001 \\
<0.001 \\
<0.001 \\
<0.001 \\
<0.001 \\
<0.10 \\
<0.001 \\
<0.02 \\
<0.001 \\
<0.001 \\
<0.02\end{array}$ & $\begin{array}{l}\text { Food eaten every } \\
\text { day }\end{array}$ \\
\hline
\end{tabular}


sucrose, there is a noticeable increase in caries. It is plausible that the blacks in this study have changed their way of life from previous generations and that they have adopted more of a white man's diet; this would include a significant increase in the consumption of sucrose between meals. With an increase in industrialization and urbanization, blacks have become more assimilated into an urban way of life than in past generations. In this setting, sucrose-containing foods become more attractive and available for consumption.

Socioeconomic status does not appear to have been an influencing factor in the results of this study, because all samples were selected from schools that are located in the lower economic areas of the cities. Schools that are located in the upper or middle socioeconomic areas were not used for the survey. Although a few participants with a higher socioeconomic status have been included because of residence, the total sample was considered to be of low socioeconomic status. Even though the socioeconomic status of the samples that were studied may not be identical, the populations generally were in the lower socioeconomic status in their respective cities. Studies have indicated that socioeconomic status has little or no effect on the total DMF teeth, but it is related to differences among the components of the DMF count; decayed and missing teeth scores are higher for low socioeconomic groups and filled rather than decayed teeth scores are higher for upper socioeconomic groups. ${ }^{10,11}$

Other investigators have concluded that the relationship of sucrose to dextran that is formed in the presence of oral streptococci facilitates the carious process by causing bacterial plaque to stick to smooth surfaces of enamel.4,12,13 Cariogenic streptococci were thought to be responsible for the initiation of smooth surface caries, but they will only produce dextran in the presence of sucrose. ${ }^{1,3,12,14}$ Sucrose consumption, therefore, might be associated more closely with caries in smooth surfaces alone than with caries scores that include lesions in pits and fissures, in which other bacteria are thought to play an etiologic role. Because of this finding, it seemed that consumption of sucrose would be related more closely to carious activity on smooth surfaces than to lesions in pits and fissures. Chi-square re- sults, however, did not support this hypothesis.

Specific cariogenic streptococci must be present, in addition to high intakes of sucrose, in the oral cavity to facilitate the initiation of caries on smooth surfaces. ${ }^{4,15-17}$ It can be hypothesized that increases in caries that were found among blacks in this study were a result of infection with specific bacteria that were responsible for dental caries in the presence of high and continuous intakes of sucrose.

\section{Conclusions}

This study was designed to obtain information about between-meal snacking patterns and to relate the differences or lack of differences in caries experience between groups with the consumption of sucrose between meals. To examine this relationship between sucrose and dental caries experience, the between-meal questionnaire was developed and administered to acquire information about the snacking habits of the populations studied.

The results from the analyses of questionnaire responses, in relation to caries experience, were not as expected. No significant relationship could be found between the consumption of sucrose-containing between-meal snacks and low, medium, and high caries experience. Analyses were conducted for total caries experience as expressed in DMF teeth and also for proximal (smooth surface) caries experience, which was thought to be related more closely to the consumption of sucrose. No clear pattern of association was found in any of these analyses. Only a few of the chi-squares that were calculated were significant; this would be expected only as a result of chance. The caries experience that was recorded in this study was the result of a lifetime exposure to the oral environment. Changes in oral flora and dietary patterns or habits, however, could occur in a short period of time. Past caries experience, therefore, does not indicate necessarily a strong relationship to snacking habits, which could have changed recently.

An examination of the data according to race, however, indicated that whites and blacks consumed a great number of betweenmeal snacks. Blacks in Detroit and Columbia consumed more snacks of all kinds (sucrose and nonsucrose) than whites. The results 
from chi-square tests revealed that an equal number of significant values supported and negated the hypothesis that high caries experience would be related to a higher consumption of sucrose snacks between meals.

In this study, caries experience was not associated with between-meal eating patterns. Lack of differences between racial and geographic groups was not related to the frequency of sucrose-containing betweenmeal snacks.

\section{References}

1. Fitzgerald, R.J., and Jordan, H.V.: Polysaccharide-Producing Bacteria and Caries, in HARRIS, R.S. (ed): Art and Science of Dental Caries Research, New York: Academic Press, 1968, pp 79-86.

2. Donahue, J.J.; Kestenbaum, R.C.; and KING, W.J.: The Utilization of Sugar by Selected Strains of Oral Streptococci, abstracted, IADR Program and Abstracts of Papers, No. 58, 1966.

3. Gibbons, R.J., and Banghart, S.: Cariogenicity of a Human Levan Forming Streptococcus and a Streptococcus Isolated from Subacute Bacterial Endocarditis, abstracted, IADR Program and Abstracts of Papers, No. 137, 1967.

4. Carlsson, J.: Plaque Formation and Streptococcal Colonization on Teeth, Odontol Revy 19:1-14, 1968.

5. Gustafsson, B.E., et al: The Vipeholm Dental Caries Study. The Effects of Different Levels of Carbohydrate Intake on Caries Activity in 436 Individuals Observed for Five Years, Acta Odontol Scand 11: 232-264, 1954.

6. Weiss, R.L., and Trithart, A.H.: Between Meal Eating Habits and Dental Caries Experience in Preschool Children, Am J Public Health 50:1097-1104, 1960.

7. Klein, H., and Palmer, C.E.: Studies on Dental Caries: X. Procedures for Recording and Statistical Processing of Dental Exami- nation Findings, J Dent Res 19:243-256, 1940.

8. Bagramian, R.A., and Russell, A.L.: An Epidemiologic Study of Dental Caries in Race and Geographic Area, J Dent Res 50: 1553-1556, 1971.

9. Fisher, F.J.: A Field Survey of Dental Caries, Periodontal Disease and Enamel Defects in Tristan da Cunha, $B r$ Dent $J$ 125:447-453, 1968.

10. Kelly, J.E.; Van KirK, L.E.; and Garst, C.C.: Decayed, Missing, and Filled Teeth in Adults, United States-1960-1962, USPHS (National Center for Health Statistics, Series 11, No. 23), Washington, DC: Government Printing Office, 1967.

11. Klein, H., and Palmer, C.E.: Community Economic Status and the Dental Problems of School Children, Public Health Rep 55: 187-205, 1940.

12. Jordan, H.V., and Keyes, P.H.: In Vitro Methods for the Study of Plaque Formation and Carious Lesions, Arch Oral Biol 11: 739-801, 1966.

13. StePhaN, R.M., and HarRis, R.M.: Location of Experimental Caries on Different Tooth Surfaces in the Norway Rat, in Sognnaes, R.F. (ed): Advances in Experimental Caries Research (A Symposium Presented on December 29, 1953 at the Boston Meeting of the AAAS), Washington, 1955, pp 47-65.

14. Frostell, G.; Keyes, P.H.; and Larson, R.H.: Effect of Various Sugars and Sugar Substitutes on Dental Caries in Hamsters and Rats, $J$ Nutr 93:65-76, 1967.

15. Carlsson, J,: Effect of Diet on Presence of Streptococcus Salivarius in Dental Plaque and Saliva, Odontol Revy 16:336$347,1965$.

16. WINTER, G.B.: Sucrose and Cariogenesis, a Review, Br Dent $J$ 124:407-411, 1968.

17. WoOd, J.M., and CritchleY, P.L.: The Extracellular Polysaccharide Produced from Sucrose by a Cariogenic Streptococcus, Arch Oral Biol 11:1039-1042, 1966. 